\title{
Lighting Quality, Productivity and Human Health
}

\author{
Ruzena Kralikova \& Emil Wessely
}
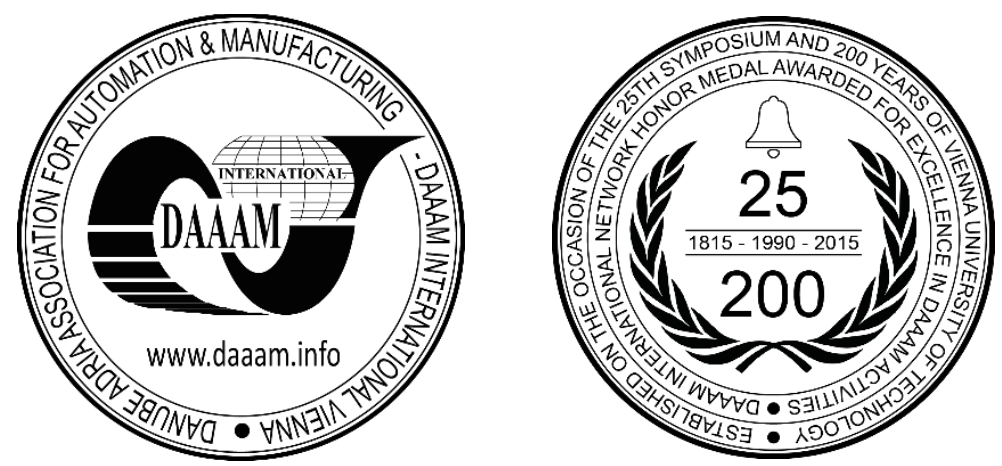

This Publication has to be referred as: Kralikova, R[uzena] \& Wessely, E[mil] (2016). Lighting Quality, Productivity and Human Health, Proceedings of the 27th DAAAM International Symposium, pp.0059-0065, B. Katalinic (Ed.), Published by DAAAM International, ISBN 978-3-902734-08-2, ISSN 1726-9679, Vienna, Austria

DOI: $10.2507 / 27$ th.daaam.proceedings.009

\begin{abstract}
Measuring the increase in productivity due to the influence of lighting is not a simple task. In a production plant, information about productivity is an important indicator of performance. This paper describes an interdisciplinary approach of experts from the fields of psychology, ergonomics, medicine and lighting technology jointly applying a set of evaluation instruments with goal to describe and analyse the effects on well-being and stress, motivation and sleeping quality, the capacity to regenerate after work, as well as the quality of the lighting situation could be useful.
\end{abstract}

Keywords: lighting quality; illuminance; productivity; working environment; visual conditions.

\section{Introduction}

Good lighting in the workplace with well-lit task areas is essential for optimising visual performance, visual comfort and ambience, especially with an ageing workforce. And the beneficial effects of good lighting extend much further than it was originally thought. In fact, over the last two decades, medical science has consistently shown that light has a positive influence on health and wellbeing. With better lighting, performance can be improved by speeding up tasks and reducing failure rates and when added to the energy saving aspects. Sustainable lighting can be a powerful tool to improve business also $[1,5]$.

Studies have shown that the body's hormone levels rise and fall during the day in response to the availability of natural light $[1,3,6,7]$. Increasing light levels make people feel energised and active but as daylight intensity diminishes, the opposite is true. Light has a profound effect on our physical and emotional health [1,17]. Good lighting solutions delivers the right level of light at different times of the day and enhances people's sense of wellbeing, improving concentration, motivation and performance. Suitable lighting at the workplace, with appropriate lighting of places of work tasks, is a prerequisite for optimizing visual performance, visual comfort and comfort of working environment, especially in the context of an aging workforce and the positive effects of adequate lighting can be extended even further [24,25].

In a production plant, information about productivity is an important indicator of performance. Measuring the increase in productivity due to the influence of lighting is not a simple task. Where an increase is observed, this may often be due to a variety of influences. In the sphere of lighting, there are many possibilities to create good visual conditions, even through static lighting meeting standard requirements as a minimum. For dynamic brightness sequences, it is possible to 
modify the brightness or colour temperature of the lighting. The effect on the workers may be assessed through various interviews, questionnaire surveys and measurements [2, 7].

\section{Lighting quality defining}

Lighting quality is depending on several factors. It depends largely on people's expectations and past experiences of electric lighting. Those who experience elementary electric lighting for the first time, for example in remote villages in developing countries, have different expectations and attitudes towards lighting from office workers in industrialized countries. There are also large individual differences in what is considered comfortable lighting, as well as cultural differences between different regions. Lighting quality is much more than just providing an appropriate quantity of light. Other factors that are potential contributors to lighting quality include e.g. illuminance uniformity, luminance distributions, light colour characteristics and glare.

There are many physical and physiological factors that can influence the perception of lighting quality. Lighting quality cannot be expressed simply in terms of photometric measures nor can there be a single universally applicable recipe for good quality lighting [8,9]. Light quality can be judged according to the level of visual comfort and performance required for our activities. This is the visual aspect. It can also be assessed on the basis of the pleasantness of the visual environment and its adaptation to the type of room and activity. This is the psychological aspect. There are also long term effects of light on our health, which are related either to the strain on our eyes caused by poor lighting (again, this is a visual aspect), or to non-visual aspects related to the effects of light on the human circadian system [4].

A number of different approaches have been suggested to define lighting quality. The definition that seems most generally applicable is that lighting quality is given by the extent to which the installation meets the objectives and constraints set by the client and the designer. In this way lighting quality is related to objectives like enhancing performance of relevant tasks, creating specific impressions, generating desired pattern of behaviour and ensuring visual comfort [10].

The constraints may be set by the available financial budgets and resources, set time-lines for completing the project and possible predetermined practices and design approaches that need to be followed. Lighting quality means achieving an optimum balance among human needs (visibility, task performance, visual comfort, health, safety, well-being, social communication, aesthetic...), architectural considerations (daylighting, standards, safety and security, composition, style) and economics, energy efficiency, environment (installation, energy saving, operation, maintenance), Figure 1 [25].

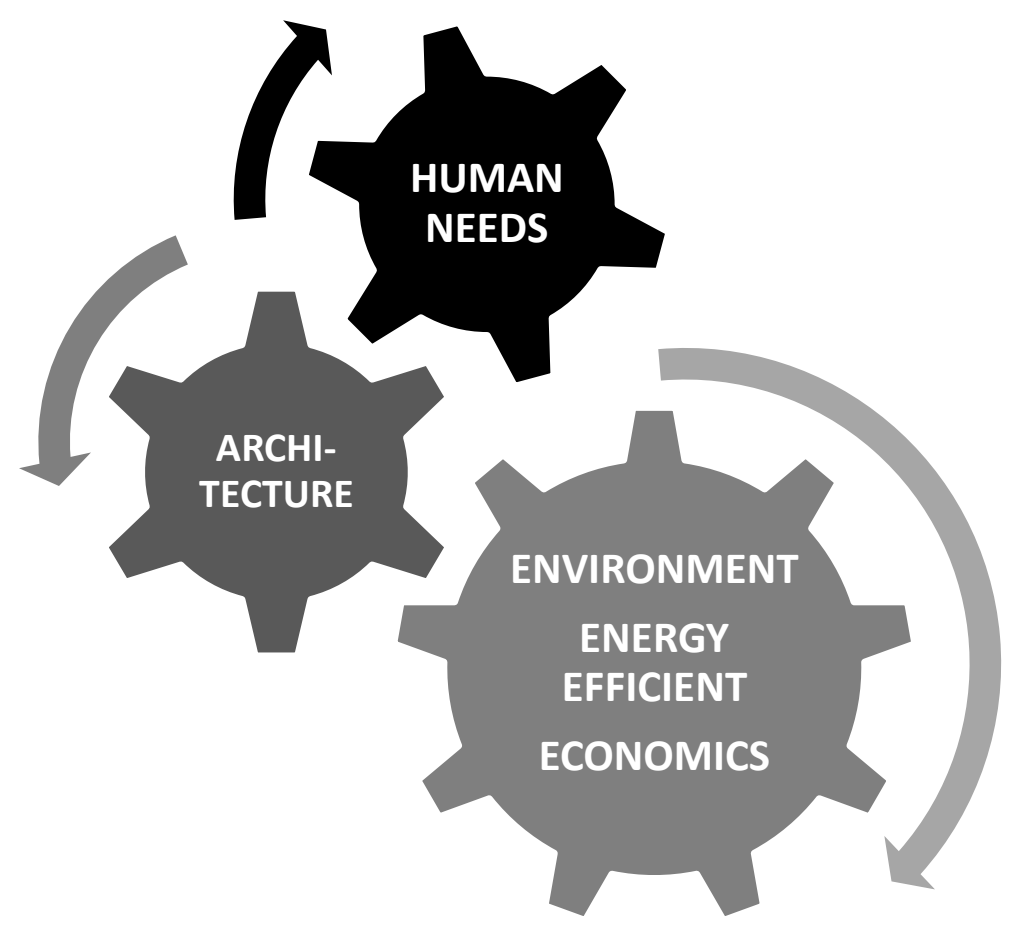

Fig.1. Lighting quality 


\section{Luminous environment and human performance}

Light has effects that are fully or partly separated from the visual system and biological effects of light, called also the non-visual and they influence on the well-being, safety work, productivity, health, social communication and aesthetic judgement.

\subsection{Visual aspects of the lighting}

The influence of artificial lighting on the psychophysiological well-being and the productivity of workers in a production plant depends on kind of lighting source that with respect to[4]:

- brightness - illuminance,

- light colour - spectrum and

- light distribution - luminance distribution in the room.

The effects of artificial lighting on people are more pronounced, that natural influence of daylight inside working hours is very low especially during winter season. One of the major aspects of the lighting practice and recommendations is to provide adequate lighting for people to carry out their visual tasks. Ensuring adequate and appropriate light levels quantity of light is only an elementary step in creating comfortable and good-quality luminous and visual environments. Lighting that is adequate for visual tasks and does not cause visual discomfort is not necessarily good-quality lighting. Depending on the specific application and case, both insufficient lighting or too much light can lead to bad-quality lighting. There are a number of lighting-related factors that may cause visual discomfort [13]. The current indoor lighting recommendations give ranges of illuminance values for different types of rooms and activities [10].

In addition, guidelines on light distribution in a space, the limitation of glare, and the light colour characteristics are given. The colour characteristics of light in space are determined by the spectral power distribution (SPD) of the light source and the reflectance properties of the surfaces in the room [16]. The colour of light sources is usually described by two properties, namely the correlated colour temperature (CCT) and general colour rendering index (CRI) [21]. The colour appearance of a light source is evaluated by its correlated colour temperature (CCT). For example, incandescent lamps with CCT of $2700 \mathrm{~K}$ have a yellowish colour appearance and their light is described as warm. Certain type of fluorescent lamps or white LEDs have CCT of around $6000 \mathrm{~K}$ with bluish appearance and light described as cool. The CRI of the CIE measures how well a given light source renders a set of test colours relative to a reference source of the same correlated colour temperature as the light source in question of International Commission on Illumination (CIE). The general CRI is calculated as the average of special CRIs for eight test colours. The reference light source is Planckian radiator (incandescent type source) for light sources with CCT below $5000 \mathrm{~K}$ and a form of a daylight source for light sources with CCT above $5000 \mathrm{~K}$. The higher the general CRI, the better is the colour rendering if a light source, the maximum value being 100. The Light source spectrum, i.e. radiant power distribution over the visible wavelengths, determines the light colour characteristics. Examples of spectra of the lamps are shown on Figure 2 - 4 [24].

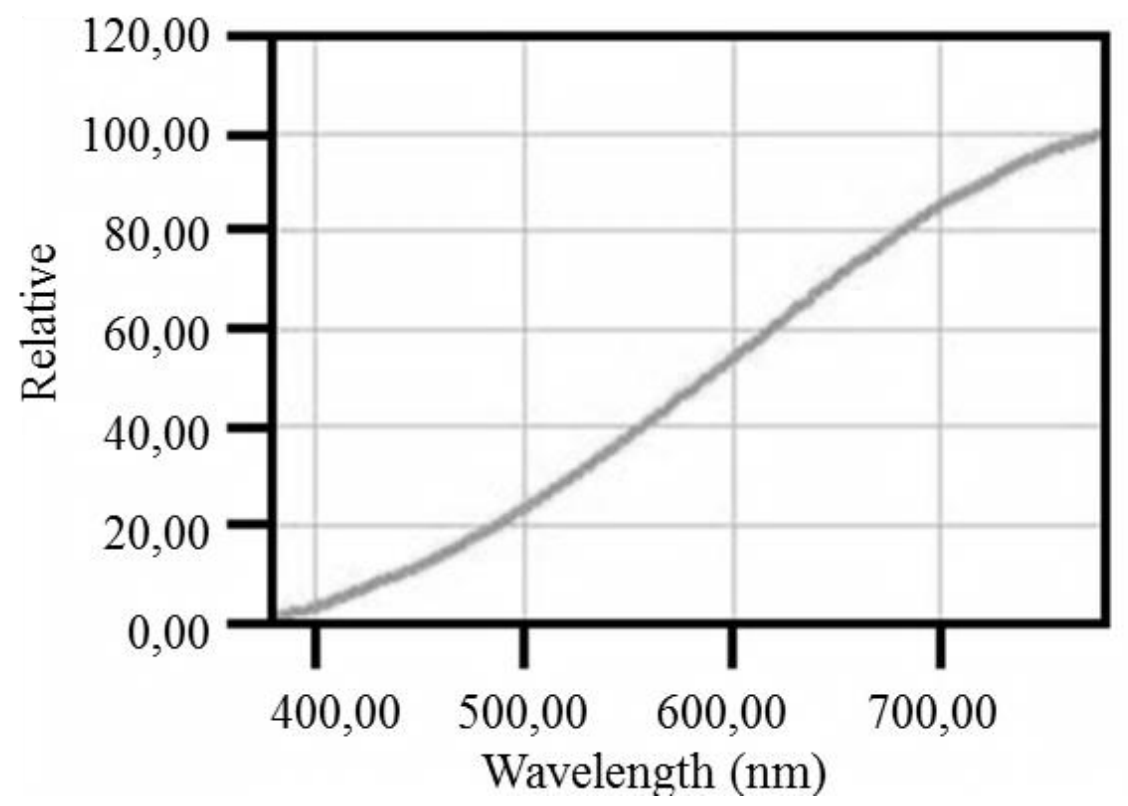

Fig. 2. Light source spectrum - Example of spectra of an incandescent lamp (CCT=2690 K, CRI=99) 


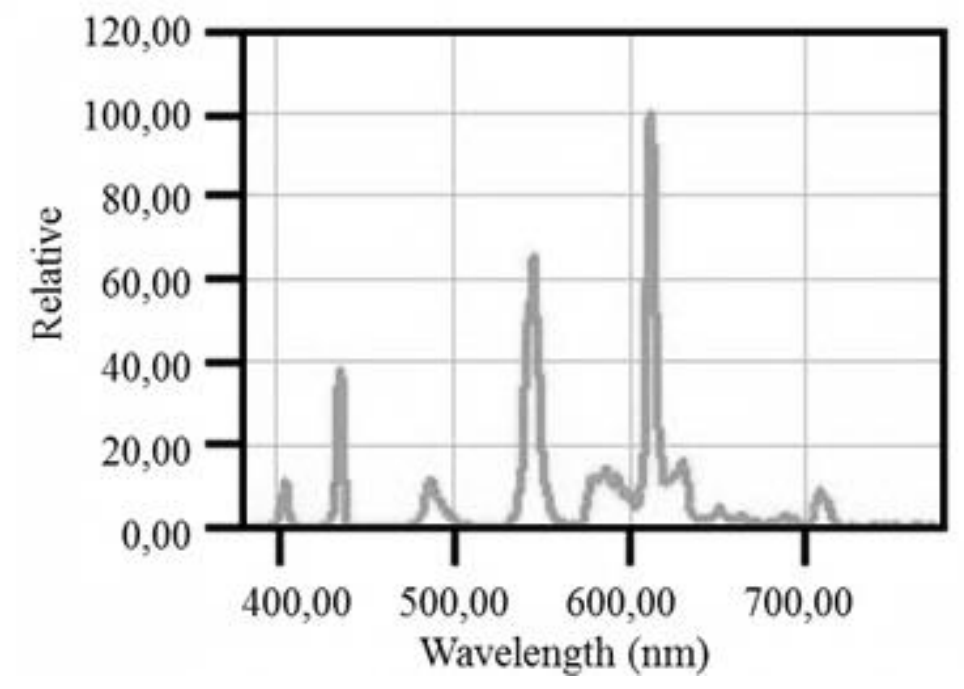

Fig. 3. Light source spectrum - example of spectra of a compact fluorescent lamp $(\mathrm{CCT}=2780 \mathrm{~K}, \mathrm{CRI}=83)$

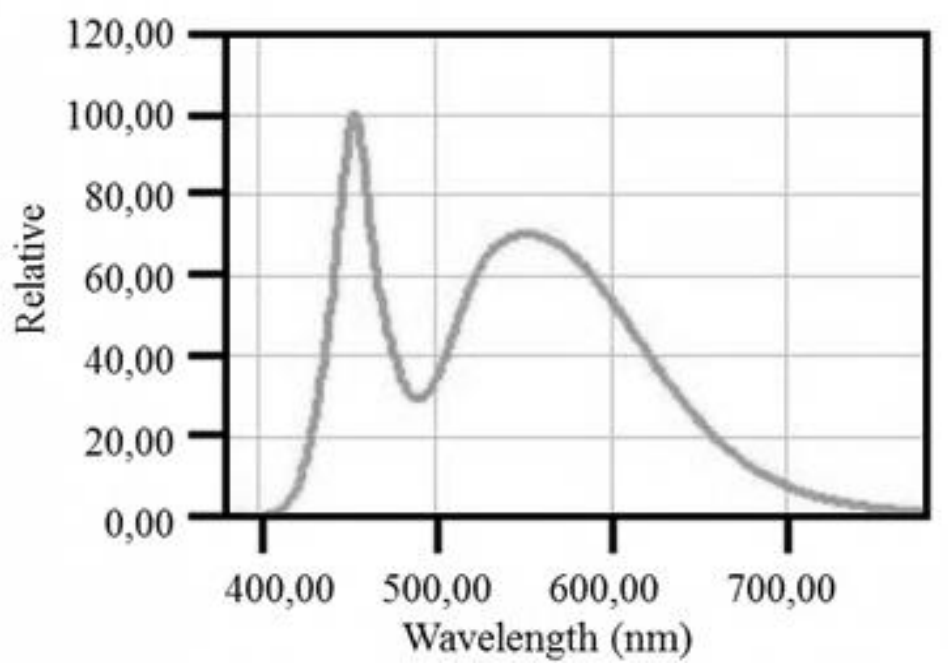

Fig. 4. Light source spectrum - example of spectra of a white LED lamp $(\mathrm{CCT}=6010 \mathrm{~K}, \mathrm{CRI}=78)$

\subsection{Lighting standards}

A completely uniform space is usually undesirable whereas too nonuniform lighting may cause distraction and discomfort. Lighting standards and codes usually provide recommended illuminance ratios between the task area and its surroundings according EN 12 464-1 [21]. Most indoor lighting design is based on providing levels of illuminances while the visual system deals with light reflected from surfaces i.e. luminances. For lighting there are recommended luminance ratios between the task and its immediate surroundings. Room surface reflectances are an important part of a lighting system and affect both the uniformity and energy usage of lighting. Compared to a conventional uniform lighting installation with fluorescent lamps, LEDs provide opportunities to concentrate light more on actual working areas and to have light where it is actually needed. This provides opportunities to increase the energy efficiency of lighting in the practise [19].

\subsection{Psychological aspects of space lighting}

Several researchers have investigated psychological aspects of space lighting $[3,17]$. The luminous environment can be perceived in many ways e.g. as more or less agreeable, more or less attractive, more or less appropriate to the function of the space, more or less highlighting the company image. Variations of luminances and colours can strengthen attractiveness, trigger emotions, and affect worker's mood, the impact of lighting depends much on the individuals and their state of mind. Unacceptable lighting conditions may impact on task performance and thus productivity through motivation. A lighting installation that does not meet the user's expectations can be considered unacceptable even if it provides the conditions for adequate visual performance. People perceive their luminous environment through their eyes [17]. 


\subsection{Biological effects of light}

Light has also effects that are fully or partly separated from the visual system. Biological effects of light are called also the non-visual effects of light, related to the human circadian photoreception. The biological effects of light and their effects on human performance are not yet very well known. Research work is needed to generate an improved understanding of the interaction of the effects of different aspects of lighting on behavioural visual tasks and cortical responses and on how the biological effects of lighting could be related to these responses [17].

The biological effects of light and their effects on human performance are not yet very well known. Lighting should be designed to provide people with the right visual conditions that help them to perform visual tasks efficiently, safely and comfortably. The luminous environment acts through a chain of mechanisms on human physiological and psychological factors, which further influence human performance and productivity, Fig.5 [6].

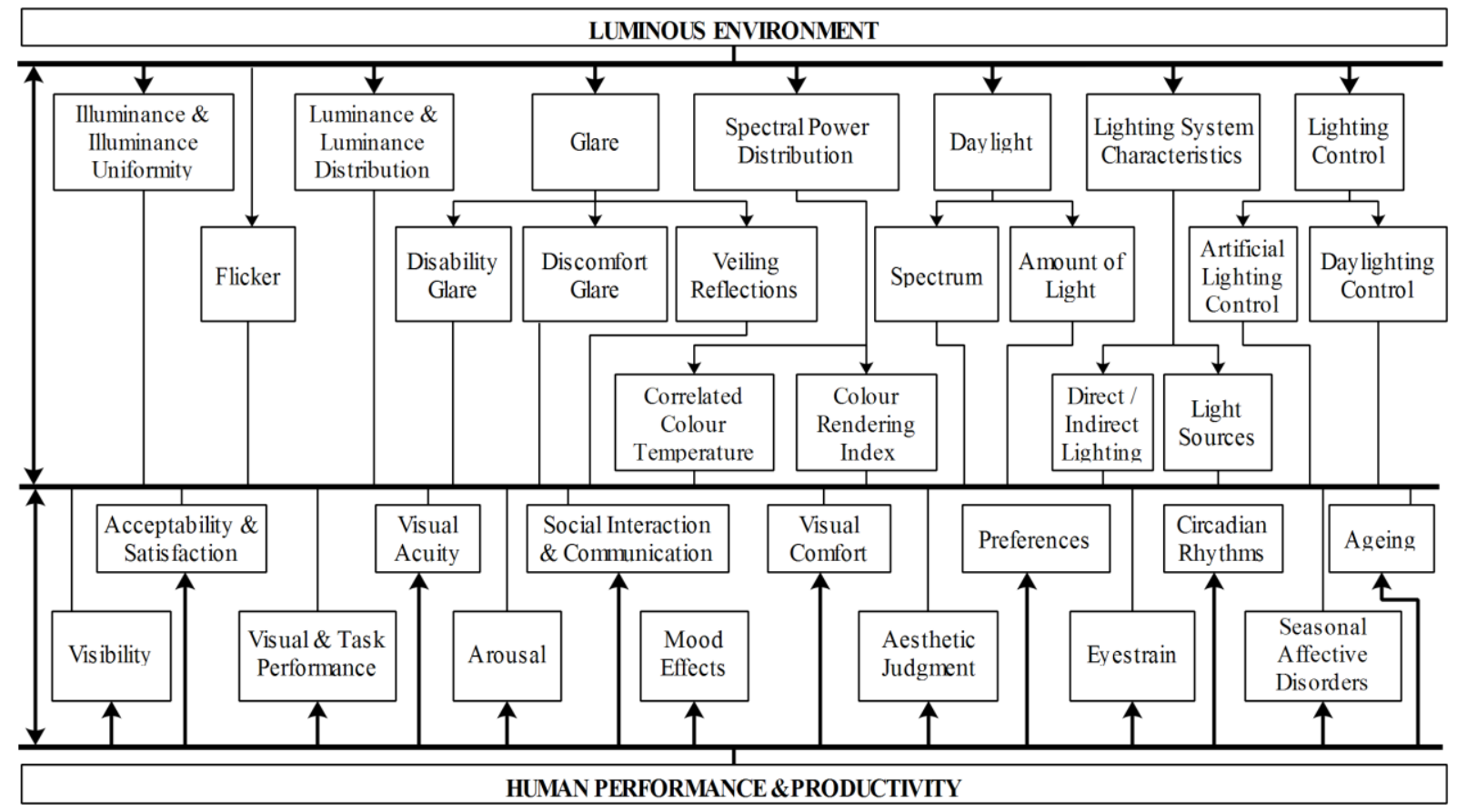

Fig. 5. Luminous environment and human performance

\section{The effect of lighting on productivity}

Lighting should be designed to provide people with the right visual conditions that help them to perform visual tasks efficiently, safely and comfortably [8]. The luminous environment acts through a chain of mechanisms on human physiological and psychological factors, which further influence human performance and productivity [6].

The effect of lighting on productivity is ambiguous. The difficulty in finding the relations between lighting and productivity is that there are several other factors that simultaneously affect human performance. These factors include motivation, relationships between workers and the management and the degree of having personal control to the working conditions $[11,22]$. With appropriate lighting the ability to perform visual tasks can be improved and visual discomfort can be avoided. This can provide conditions for better visual and task performance and, ultimately, productivity.

The difficulty of field studies in working environments is the degree of experimental control required. Several studies have investigated the effect of increase in illuminance on task performance. However, illuminance is only one of the many aspects in the lighting conditions. In making changes to lighting, which lighting aspects are changed (e.g. illuminance, spectrum, and luminance distribution) and whether there are other factors that are simultaneously changed in the working conditions (e.g. working arrangements, people, supervision of work) need to be controlled and analysed. Recently, several studies are investigating the effects of light spectrum on human performance and the possibilities to use blue-enriched light to improve human performance through the non-visual effects of light. Poor lighting conditions can easily result in losses in productivity of employees and the resulting production costs of the employer can be much higher than the annual ownership cost of lighting.

\section{Discussion}


The effects of lighting conditions on productivity have been published in the several studies the earliest studies indicated that lighting conditions can improve performance by providing adequate illuminance for the visual tasks. Their results are sometimes contradictory. For example, a study in office work indicated that an increase in illuminance from $500 \mathrm{~lx}$ to $1500 \mathrm{~lx}$ could increase the performance of office workers by $9 \%$, while another study showed that lower illuminance levels $(150 \mathrm{~lx})$ tended to improve performance of a complex word categorisation task as compared to a higher level (1500 lx) [1, 5, 11].

A field study in industrial environment measured direct productivity increases in the range from 0 to $9 \%$ due to changes in lighting. The literature shows some examples of null results than clear-cut effects of illuminance on task performance, over a wide range of illuminance levels and for a variety of complex and simple tasks in working environment [5].

\section{Conclusion}

Observing the effect of light on human beings and health is a topic that is addressed by various sciences such as psychology, medicine, ergonomics and lighting technology. The interdisciplinary application of methods shows that measuring the effect of lighting on human beings is complex. If no results are obtained, that does not mean that there is no effect, but that the instruments of observation and measurement have not been optimally used. Further efforts are required to improve the measuring methods, instruments and evaluations.

Here are a few guidelines how can to create a setting that increases the satisfaction and productivity:

- Take the biological aspect of lighting into account. Light synchronises the circadian rhythm and it influences to sleepwake cycle and this has a big influence on people health and productivity.

- Adapt the lighting to the daytime and season and to the individual needs of the user.

- Provide adequate lighting for people to carry out their visual tasks, create a sense of space and depth gives a visual comfort and adds a pleasant atmosphere to the working environment.

From research studies Good lighting creates pleasant working conditions in a functional and atmospheric way. Both daylight and artificial light play a key role in our health and wellbeing. Satisfaction and efficiency will improve if will enough daylight intake and a well-lit working space. Artificial lighting that does not just help you see, but also meets your biological lighting needs, is the future of work space lighting. Productivity, visual comfort and employees health will be positively affected by well-designed illumination.

\section{Acknowledgments}

The research in this paper was supported by a grant „, Research of influence of chosen parameters of working environment on working power and productivity" VEGA - No 1/0537/2015 supported by Slovak Research and Development Agency (SRDA).

\section{References:}

[1] Boyce, P. R. (2004). Lighting research for interiors: the beginning of the end or the end of the beginning. In: Lighting Research and Technology.Vol. 36,No.4, 2004), pp.283-293.

[2] Chin Kim Gan; Ahmad Farid Sapar; Yik Chee Mun \& Kuan Eng Chong (2013). Techno-Economic Analysis of LED Lighting (2013): A Case Study in UTeM's Faculty Building, Procedia Engineering, Vol. 53, 2013, pp. 208-216, ISSN 1877-7058.

[3] Durak, A. ; Olguntürk, N. C.; Yener, C.; Güvenç, D. \& Gürçınar, Y. (2007). Impact of lighting arrangements and illuminances on different impressions of a room. Building and Environment, 42(10), 3476-3482.

[4] Frumkin, H. (2003). Healthy places: exploring the evidence. In: American journal of public health , Vol. 93,No.9, 2003, pp.1451-1456.

[5] Gligor, A.; Grif, H.; \& Oltean, S. (2006). Considerations on an intelligent buildings management system for an optimized energy consumption. In: Automation, Quality and Testing, Robotics, IEEE International Conference on. IEEE, 2006, pp. 280-284.

[6] Gligor V. (2004). Luminous Environment and Productivity at Workplaces. Thesis, 2004. Espoo:Helsinki University of Technology.

[7] Hughes, P. C. \& McNelis, J. F. (1978). Lighting, productivity, and the work environment. Lighting Design and Application, Vol. 8, No.12, 1978, pp.32-38.

[8] Kadir Amasyali \& Nora El-Gohary (2016). Building Lighting Energy Consumption Prediction for Supporting Energy Data Analytics, Procedia Engineering, Vol. 145, 2016, pp. 511-517, ISSN 1877-7058.

[9] Kõrbe Kaare,K. \& Tauno O.( 2015). Smart Health Care Monitoring Technologies to Improve Employee Performance in Manufacturing, Procedia Engineering vol.100.2015, pp. 826 - 833. 
[10] Leppiman, A.; Kotka, T.; Kõrbe Kaare, K. \& Koppel, O.(2015). Decision-making framework for industrial-size datacenters. Proceedings of the International Conference of DAAAM Baltic "Industrial Engineering", 2015-January, pp. 237-242.

[11] Manlig, F.; Šlaichová, E.; Koblasa, F. \& Vavruška, J. (2014). Innovation of business processes by means of computer-aided simulation Applied Mechanics and Materials, 474, pp. 67-72.

[12] Micieta, B. \& Binasova, V. (2013). Defining requirements for energy efficiency in manufacturing. DAAAM International Scientific Book 2013, pp. 887-894. ISSN 1726-9687.

[13] Micieta, B.; Markovic, J. \& Binasova, V. (2016). Advances in sustainable energy efficient manufacturing system, MM Science Journal, 2016-June, pp. 918-926.

[14] Petek, J.; Glavič, P. \& Kostevšek, A. (2016). Comprehensive approach to increase energy efficiency based on versatile industrial practices, Journal of Cleaner Production, Vol. 112, 2016, pp. 2813-2821.

[15] Perlova,E.; Platonova,M.; Gorshkov, A. \& Rakova, X. (2015). Concept Project of Zero Energy Building, Procedia Engineering. Vol. 100. 2015. pp. $1505-1514$.

[16] Varga, G.; Szigeti, F. \& Deszö, G. (2015). Examination of surface roughness of burnished workpieces In: Scientific Bulletin: Mechanics, Tribology, Machine Manufacturing Technology. Vol. 29, 2015, pp. 94-98, ISSN: $1224-3264$.

[17] Veitch, J.A. (2001). Psychological processes influencing lighting quality. In: Journal of the Illuminating Engineering Society, Vol. 30, No. 1, 2001, pp.124-140.

[18] Murgul V.; Vatin N. \& Zayats, I. (2015). The Role of the Solar Light Quantity in the Architectural Forming of Buildings, Procedia Engineering, Vol. 117, 2015, pp. 819-824, ISSN 1877-7058.

[19] Vuorio, J.; Nikkilä, V.; Teivastenaho, V.; Peltola, J.; Partanen, J.; Kiviluoma, P. \& Kuosmanen P. (2014). Additive Manufacturing with UV Light Cured Resin, 9th International DAAAM Baltic Conference "INDUSTRIAL ENGINEERING" 24-26 April 2014, Tallinn, Estonia, pp. 317-322.

[20] Wei Li, Jinzhong Zhu \& Zhimin Zhu (2012). The Energy-saving Benefit Evaluation Methods of the Grid Construction Project Based on Life Cycle Cost Theory, Energy Procedia. Vol.17(A), 2012. pp. 227-232.

[21] EN 12464-1, Light and lighting - Lighting at work places - Part I: Indoor Work Places, European Standard.

[22] European Directive 2006/25/EC, 2006. On the minimum health and safety requirements regarding the exposure of workers to risks arising from physical agents (artificial optical radiation). Official Journal of the European Union, L 114, 38-59

[23] http://www.aivc.org/sites/default/files/members_area/medias/pdf/Conf/2002/109_076\%20Halonen.pdf

[24] The Lighting Handbook, available: http://www.zumtobel.com/PDB/teaser/EN/lichthandbuch.pdf

[25] https://www.iald.org/Advocacy/Advocacy/Quality-of-Light 